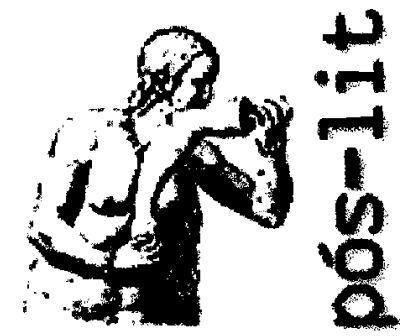

Programa de Pós-Graduação em Letras: Estudos Literários da Faculdade de Letras da UFMG

Artigo disponível em http://www.letras.ufmg.br/poslit

\section{O SABER E A VERDADE NA LÍNGUA: A QUESTÃO DA LITERATURA}

Marcelo Jacques de Moracs
Dans l'article suivant, je prétends à introduire des paramètres pour une discussion sur la distinction possible, du point de vue conceptuel, entre le champ linguistique et le champ poétique. Pour atteindre ce but, je discuterai la tension constante entre les notions du Sayoir et de la Vérité à travers d'une confrontation téorique entre la linguistique et la psychanalyse à partir des concepts élaborés par Patrick Charaudeau et Jacques Lacan. 
Nas primeiras linhas de um livro intitulado $O$ amor da língua, Jean-Claude Milner afirma que “a palavra (...) não vai em todos os sentidos, [uma vez que se choca] incessantemente com o fato de que tudo não se diz". Esta afirmação pode ser compreendida no seio de dois campos teóricos completamente distintos, no entrecruzamento dos quais o autor trabalha: o campo da lingüística e o da psicanálise. Pois para a primeira, tanto quanto para a segunda, jamais se pode dizer tudo, na medida em que há sempre um real da língua a coagir, a forçar uma fronteira entre o possível e o impossível de dizer, entre o que é dizível e o que é indizível.

Entretanto, enquanto a maioria dos lingüistas, diante de uma manifestação discursiva qualquer, está mais interessada na impossível tarefa de esgotar o campo do comunicável que ali se desenha, o interesse dos psicanalistas incide principalmente sobre a tarefa - ela também certamente impossível - de apreender, diante da mesma manifestação, o incomunicável que nela, de algum modo, produz falhas. Em outros termos, se o que atrai o lingüista é o que há de regular, de calculável, na língua, isto é, sua consistência, o que seduz o psicanalista é, ao contrário, sua inconsistência, isto é, o excepcional, o incalculável pelo qual ela se deixa incessantemente penetrar e que insiste, impedindo a língua de traduzir-se numa mensagem clara e distinta, como diria Descartes.

Ocorre, portanto, que o tudo do qual Milner diz que não é dito implica para um lingüista algo completamente diferente do que para um psicanalista: para o primeiro, trata-se de fazer a partição entre o correto e o incorreto na língua (e portanto de discernir o que ela deve dizer, segundo as palavras célebres de Jakobson) ${ }^{2}$; já para o segundo, trata-se de uma impossibilidade estrutural da própria linguagem que faz com que, segundo as palavras não menos célebres de Jacques Lacan, a verdade não se diga toda, e isto "porque dizê-la toda é impossível, materialmente: as palavras faltam".

Sendo feita esta distinção, arrisco uma primeira colocação do que quero aqui, ainda que brevemente, desenvolver: se o lingüista busca, de certa forma, o universal da língua, isto é, aquilo que faz com que se estabeleça uma correspondência biunívoca entre o que diz (ou escreve) um indivíduo e o que ouve (ou lê) um outro indivíduo, que faz com que haja coincidência entre enunciação e enunciado - em suma, que faz com

1. MILNER, 1978. p.7.

2. Cf. JAKOBSON, 1978. Aspectos lingǘsticos do comunicasōo, p.69.

3. LACAN, 1974. p. 9. que se produza uma comunicação - , se ele deixa de lado o excedente de sentido que é apontado pela hipótese do inconsciente e que singulariza toda manifestação discursiva, o campo do poético fica à margem de seu campo de ação. Pois se este é o campo em que, por excelência, o discurso não mais é um veículo de transmissão de algo que o precede — uma mensagem conhecida previamente pelo indivíduo que vai enunciá-la, um estado de coisas pertencente ao domínio de seu saber - , mas, antes de tudo, a constituição de um excesso de sentido que transborda do próprio discurso do qual emerge, exigindo, ao infinito, o engendramento - a enunciação - de outros discursos que possam decifrar - ou, antes, construir — os sentidos do primeiro - e, tentarei demonstrá-lo, estaríamos aqui no domínio do equívoco e portanto da dissolução de todo saber prévio, isto é, no domínio da Verdade —, como supor que possa aí haver uma perspectiva finita de configuração de sentidos?

Lingüístico e poético, universal e singular, consistência e inconsistência, Saber e Verdade. Eis os significantes que quero confrontar aqui, a fim de refletir sobre a margem que os separa e sobre a apropriação (ou expropriação) da língua que se realiza na atividade poética e que, quero supor, a define enquanto tal.

Afirmar, como eu dizia acima, que os lingüistas o fazem, que há a possibilidade de prever a rede de compreensão possível do que é, num dado momento, dito, equivale, parece-me, a afirmar que a língua é consistente, isto é, que ela é Una, ou, como diz Milner, "sempre inscritível na esfera da univocidade" . Tal enunciado, segundo Oswald Ducrot, por exemplo, designa necessariamente, por força da significação da frase que o exprime, senão tais sentidos imediatos, ao menos o que é preciso buscar no contexto em que a enunciação ocorreu para que estes sentidos sejam trazidos à luz. ${ }^{5}$

E se estes sentidos são comunicados, se eles consistem, é precisamente porque a significação da frase que os implica não admite equívocos; pois, como afirma Ducrot, "a frase indica como se pode e como não se pode argumentar a partir de seus enunciados", ${ }^{6}$ ou seja, ela permite fazer, ao menos hipoteticamente, o levantamento das "associaçóes discursivas que constituem o que Patrick Charaudeau denomina atividade serial"?

4. MILNER, op. cit. p. 20

5. Cf. DUCROI. Argumentoģoo e topoi orgumentativos. In: GUIMARÄES, 1989. p.14.

6. Ibiden. p.18.

7. CORREAA, 1991. p.24. 
Não é por acaso que cito aqui Charaudeau. É ele que, segundo me consta, ao denunciar "a abstração ideal de um modelo de competência supostamente perfeito", ${ }^{8}$ vai colocar mais claramente, do ponto de vista da lingüística, a questão do sujeito do inconsciente, nitidamente inspirado pela teoria psicanalítica lacaniana. Quando afirma, por exemplo, que "o ato de linguagem não é inteiramente consciente e que ele é subsumido por um certo número de rituais sócio-linguagísticos", ou que "o sujeito pode ser considerado como um lugar de produção da significação linguagística ao qual retorna esta significação para constituí-lo", 10 Charaudeau não está longe da demonstração empreendida por Lacan no que se refere à alienação primordial do indivíduo na linguagem "pela razão primeira que a linguagem com sua estrutura preexiste à entrada que nela faz cada sujeito num momento de seu desenvolvimento mental"." Se assim for, este sujeito do qual Lacan põe o estatuto, e que, antes mesmo de seu aparecimento enquanto tal, já se encontra inscrito numa certa rede significante (familiar, social, etc.) que o marcará para sempre, corresponde de algum modo ao "parceiro" que é atualizado na "relaçāo contratual" do ato de linguagem tal como esta é definida por Charaudeau.

Entretanto, ao sustentar que "o discurso pode ser relacionado com um conjunto de saberes compartilhados, construído na maior parte do tempo de maneira inconsciente pelos indivíduos de um grupo social", ${ }^{12}$ e assim reafirmar a possibilidade de um "sujeito analisante" de "dar conta dos possíveis interpretativos" ${ }^{13}$ isto é, de resgatar os saberes compartilhados entre os parceiros do ato de linguagem, Charaudeau recupera de algum modo uma certa "referencialidade", objetivável e intrínseca a este ato, e negligencia a radicalidade do Lacan dos anos 70 , que havia tentado demonstrar que se o ser veicula o saber, se ele o reproduz ao pé da letra, do ponto de vista do inconsciente, ele o contamina sempre com sua própria letra, com seu próprio ser ${ }^{14}$ ou ainda, para empregar uma vez mais a expressão de Charaudeau, com sua atividade serial pessoal, com esta atividade que é sempre por definição, em termos lacanianos, não

\section{CHARAUDEAU, 1984. Une théorie des sujets du langage, p.40.}

9. Ibidem. p.43.

10. Ibidem. p.42.

11. LACAN, 1966. p. 495.

12. CHARAUDEAU, op. cit. p. 40 .

13. CORREA, op. cit. p. 21.

14. C. LACAN, 1982. p. 131. compartilhável, já que, no limite, é impossível reconstituí-la em sua totalidade. Haveria portanto sempre uma margem de desconhecido, de não sabido - de inconsciência - em qualquer manifestação discursiva.

É neste sentido que Lacan vai forjar o conceito de alíngua, definido num certo momento por Milner como "uma língua entre outras, (...) que, por se colocar, impede por incomensurabilidade de construir uma classe de línguas que a inclua", ${ }^{15}$ isto é, como uma língua única, que não se deixa assimilar por nenhuma outra, que não compartilha com nenhuma outra os saberes passíveis de nela se inscreverem.

Eis portanto que, se o lingüista se dedica a erigir como saber constituído as regularidades acumuladas no passado de uma língua, de modo a poder repertoriar, em cada ato de linguagem nesta língua, os sentidos possíveis, o psicanalista, por sua vez, propõe-se a interrogar o que Lacan, no rastro de Freud, chamava de formaçōes do inconsciente, as quais, suspendendo de algum modo o sentido pretendido pelo comunicante, indicavam, por homofonia, homossemia ou homografia (ou seja, como Lacan enfatizou, por um fato de ambigüidade - ou de equívoco - lingüística) o caminho a seguir no por-vir da verdade.

Com o intuito de esclarecer um pouco esta distinção entre saber e verdade, invoco aqui o filósofo francês Alain Badiou, que tem trabalhado exaustivamente a questão. Em seu Manifesto pela filosofia, ele afirma, por exemplo:

Chamemos de situação (...) um estado de coisas, um múltiplo qualquer apresentado [isto é, um saber acumulado]. Para que se manifeste um procedimento de verdade relativo à situação, é preciso que um evento puro suplemente esta situação. Este suplemento não é nem nomeável nem representável pelos recursos da situação (sua estrutura, a língua estabelecida que nomeia seus termos, etc.). Ele é inscrito por uma nomeação singular, a colocação de um significante a mais. ${ }^{16}$

Assim, se há equívoco, se há não-senso - e, como acabamos de ver, para Lacan, sempre há —, é porque há sempre saberes ainda não compartilhados, precisamente porque ainda não constituídos por um "procedimento de verdade". Ou seja, enquanto o saber se oferece como um estado de coisas (o sistema de regras a que deve obedecer o comunicante

15. MLLNER, op. cit. p. 21. $O$ conceito de olíngus é esboccado por Locon no último copítulo de seu 0 seminório, $X X X$ desenvolvido sabretudo em L'étourdit, publicado no revisto Scilicet 4 (Paris, Seuil, 1973).

16. BADIOU, 1989. p. 17. 
de uma língua qualquer num dado momento de sua evolução, por exemplo), sob a forma de fatos realizados no passado que permitirão supor, precisamente, que uma verdade terá sido esta verdade, aparecendo sob a forma de potência a se realizar, apresenta-se sempre como um evento novo previamente indeterminável (o advento de um poeta que viole as regras em vigor de uma língua, por exemplo, exigindo, por isso mesmo, o estabelecimento de novos critérios de regulamentação para esta língua), evento que se confirma como pertinente à ordem da verdade pelo fato de inscrever-se, no só-depois da teorização, como saber. O que de alguma forma se deixa ler no texto de Peirce, quando este diz que

tudo aquilo que é verdadeiramente geral relaciona-se com o futuro indeterminado, porque o passado contém apenas uma coleção de casos que efetivamente se realizaram. O passado é de fato puro. Mas uma lei geral não pode se realizar plenamente. É uma potencialidade; e seu modo de ser é esse in futuro. ${ }^{17}$

Não se pode no entanto negar que Charaudeau também faz um grande esforço para dar conta da questão, e quase é bem sucedido quando, por exemplo, distingue, a propósito dos "efeitos de discurso" que se produzem no "lugar da palavra", os "efeitos possíveis" e os "efeitos produzidos"; entretanto, estas duas possibilidades se reportam sempre ou a um saber prévio ou a um "poder fazer" destinatário, no caso dos efeitos produzidos, e ao analisante do ato de linguagem, no caso dos efeitos possíveis), ignorando portanto a perspectiva de um ato de linguagem concernente à verdade, isto é, aquele que permitirá a instauração de um novo saber no campo da situação.

Em todo caso, parece-me que esta diferença de perspectiva se deve bem mais ao fato de que se está lidando com objetos distintos do que a uma incompatibilidade teórica: enquanto Lacan visa à emergência da verdade do sintoma do sujeito para que este possa constituí-lo como saber, Charaudeau está em busca do saber que está em jogo na encenação de um ato de linguagem e que permite compreender seus efeitos.

Mas uma vez que o que nos interessa aqui, em última instância, é o trabalho poético — o do escritor —, seria preciso recolocar a questão a partir da perspectiva da escritura. E neste momento, eu não poderia deixar de aludir a um artigo de Roland Barthes, no qual ele vai tentar distinguir a escritura, sempre intransitiva, da escrevência, que, sendo transitiva,

17. PEIRCE, citodo por Jokobson em Á procuro do essêncio do linguagem. In: JAKOBSON, op. cit. p. 117.

18. Cf. CHARAUDEAU, op. cit. p. 44,46 e 51 coloca-se a serviço da comunicação. ${ }^{19}$ Transcrevo aqui uma passagem que resume de uma certa forma a reflexăo de Barthes a propósito da questão da relação entre língua, saber e verdade.

Os escreventes, escreve Barthes, são homens "transitivos"; eles põem um fim (testemunhar, explicar, ensinar) do qual a palavra não é senão um meio; para eles, a palavra suporta um fazer, ela nāo o constitui. Eis portanto a linguagem reconduzida à natureza de um instrumento de comunicação, de um veículo do "pensamento". (...) O escrevente não exerce nenhuma ação técnica essencial sobre a palavra; ele dispôe de uma escritura comum a todos os escreventes, (...) na qual se pode, certamente, distinguir dialetos (por exemplo marxista, cristão, existencialista), mas muito raramente estilos. Pois o que define o escrevente, é que seu projeto de comunicação é ingênuo; ele não admite que sua mensagem se volte e se feche sobre si mesma, e que se possa nela ler, de uma maneira diacrítica, outra coisa além do que ele quer dizer (...). Ele considera que sua palavra põe fim a uma ambigüidade do mundo, institui uma explicação irreversível (mesmo que ele a admita como provisória), ou uma informação incontestável (mesmo que ele se queira um modesto professor [enseignant]) (...). ${ }^{20}$

Desta forma, a escrevência só poderia ser, de fato, referencial, haveria um querer dizer que a precederia e que reportaria a um saber constituído avant la lettre ("marxista, cristão, existencialista", como exemplifica Barthes, ou ainda, eu diria, lingüístico, psicanalítico), e que, além disso, pretenderia se superpor à realidade lingüística que o exprime. O escritor, ao contrário, seria "o único, por definição, a perder sua própria estrutura e a do mundo na estrutura da palavra" ${ }^{\prime 2}$, uma vez que, como observa Barthes, "a matéria-prima [da literatura torna-se] de algum modo seu próprio fim" "12.

Esta distinção tão radical entre o escrevente e o escritor peca um pouco, a meu ver, por seu formalismo excessivo, na medida em que, diante da perspectiva teórica que estou tentando expor, parece-me impossível pensar a possibilidade de um escritor puro, tal como o concebe Barthes. Neste sentido, creio que a crítica de Terry Eagleton à "estetização do valor" ${ }^{\text {" 3 }}$ que caracteriza o pensamento contemporâneo, e que, segundo ele, teria sido implicada pela progressiva desvinculação entre a produção cultural e

19. Cf. BARTHES, 1974, Écrivoins et écrivonts, p.147-154

20. ibidem. p. 151.

27. Ibidem. p. 149

22. bidem. p. 148.

23. Cf. EAGLETON, 1993. As reflexōes sobre este tópico se encontram sobretudo no último copífulo do livro, intitivlado "Do Polis on Pós-modernismon. 
as "funções sociais a que ela servia tradicionalmente", ${ }^{24}$ é mais do que precisa.

Voltando a Barthes e à literatura, não podemos negar que a suposta auto-referencialidade da obra literária reencontra freqüentemente o mundo referencial das coisas, na medida em que nela — onde só havia perguntas -, vemos respostas que, ao mesmo tempo em que subvertem nosso saber compartilhado sobre o mundo e nosso poder fazer no mundo (o das palavras e o das coisas, bem entendido), ensinam-nos um novo repertório de possibilidades de responder às questões que nos são colocadas no e pelo mundo; ou, dito de outra maneira, esta subversão operada por um "procedimento de verdade" no interior de um mundo de palavras o ultrapassa e constitui novas referências que se dispóem para que possamos utilizá-las em nossas relações com o mundo das palavras e com o mundo das coisas.

O objetivo deste texto não foi tanto o de chegar a uma conclusão sobre o processo de enunciação quanto o de tentar estabelecer um ponto de partida para um exame do que deve ser posto em jogo na distinção entre uma enunciação lingüística qualquer e uma enunciação especificamente poética, literária, e sobre a possibilidade mesma de estabelecer esta distinção.

O elemento fundamental para uma tal distinção parece-me repousar, de acordo com a perspectiva teórica aqui proposta, sobre a tensão permanente entre saber e verdade, tensão que, ao que me parece, encontrase recalcada na enunciação lingüística, que se presta à comunicação de uma mensagem qualquer no interior de um mundo já constituído, e exposta na enunciação poética, que serve à possibilidade de constituir um novo mundo.

Mas se, conforme demonstra a psicanálise, o recalcado se caracteriza precisamente pelo fato de retornar ali mesmo onde ele está supostamente elidido, a enunciação lingüística, dissecada até a exaustão, pode se prestar ao equívoco tanto quanto a enunciação poética, dizendo muito mais do que aquilo que o indivíduo que a enuncia tem a intenção de dizer e, assim, decepcionando sempre, de algum modo, a expectativa de comunicação, que seria seu objetivo por excelência.

Por outro lado, na medida em que, como diz Gilles Deleuze, no rastro de Proust, o escritor é aquele que "inventa na língua uma nova língua,

24. Ibidem. p. 12. uma língua estrangeira", ${ }^{25}$ a enunciação poética é o que vem suspender, ainda que provisoriamente, todo saber lingüístico, exigindo sua reformulação em função das novas perspectivas de sentido que ela autoriza e que não podem ser antecipadas segundo os modelos de interpretação lingüística em vigor.

Se assim for, a distinção de que estou tratando aqui incide muito mais sobre o desejo (no sentido estritamente psicanalítico, bem entendido) que produz o sujeito da enunciação do que sobre a própria enunciação. E, neste sentido, eu concluiria provisoriamente - já que toda conclusão não pode ser senão provisória - que se o sujeito da enunciação lingüística é produzido por um enunciado que visa transmitir um certo saber sobre o mundo, o sujeito da enunciação poética resulta do intuito de instaurar, através deste saber que a língua suporta, uma verdade no mundo, a qual, uma vez absorvida e assimilada enquanto saber, não somente põe à disposição dos homens novas possibilidades lingüísticas de produção de sentidos, alargando, por assim dizer, a margem expressiva da língua, como também - e sobretudo - se torna um novo objeto de saber, ele também passível, por sua vez, de transmissão.

É neste sentido, creio eu, que Jean Starobinsky vai afirmar, num artigo em que discute as relações entre a Literatura e a História da Literatura, que

a originalidade, a individualidade [de uma obra] se destacam sobre um fundo constituído pela massa coletiva dos recursos da linguagem, das formas literárias recebidas, das crenças, dos conhecimentos, que ela reativa, que ela critica, e aos quais ela se acrescenta. ${ }^{26}$

Assim, a meu ver, é no vácuo entre a transmissão de significações e instauração de sentidos que reside toda a questão da literatura. E é precisamente a partir de uma certa perversão de um legado recebido de outros escritores que um escritor, através do "procedimento de verdade" em que se constitui sua própria obra, "inventará", sem o saber, o "significante novo" pedido por Lacan." Este significante novo, que, irredutível a quaisquer significações cristalizadas, produz incansavelmente cadeias e cadeias de outros significantes nem sempre tão novos, mas que o enraízam definitivamente na própria língua, é seu próprio nome.

25. DELEUZE, 1993. p. 9 .

26. STAROBINSKY, Littéroture. In: LE GOFF, NORA, 1974. p. 228

27. Cf. LACAN, J. Vers un signifiant nouveau. In: Ornicar?, no 17/18, p. 7-23. 
Vale aqui uma observação, que, creio eu, justifica plenamente esta última afirmação. Se é, como afirmei, a partir de um certo Saber constituído que se pode formular uma Verdade, esta jamais escapa impunemente das formas, dos caldos culturais nos quais se entreteceu. Assim, o único significante que se pode ter como radicalmente novo é o nome próprio que passa a freqüentar a língua como um nome comum, ou melhor, como um adjetivo designando uma certa maneira de olhar, uma certa maneira de proceder sobre o mundo. Apresento aqui uma definição do conceito de Sujeito, dada pelo psicanalista brasileiro M. D. Magno que me parece enquadrar-se bastante bem neste registro. Diz ele:

Lembrem-se de que um Sujeito, se o considerarmos como considero, não é bem um subjectum e menos ainda um objectum, mas sim, na dependência do eventural, é mesmo um adjectum, a se verificar sódepois, como é claro. ${ }^{28}$

É neste sentido que quero compreender a fórmula desenvolvida por de Thierry de Duve em seu livro $A u$ nom de l'art e que dá título a um de seus artigos: "A arte era um nome próprio". ${ }^{29}$

\section{REFERENCIAS BIBLIOGRÁFICAS}

BADI0U, A. Manifeste pour la philosophie. Paris: Sevil, 1989.

BARTHES, Roland. Essais critiques. Poris: Sevil, 1974

CHARALDEAU, P. Une théorie des sujets du longage. In: Longoge et societét. Paris, Maison des Sciences de l'Homme, 28: 37-51 Divin 1984, p. 40

CORPÊA, A. M. S. Erros em trodus̄̄o do froncês paro o portugués: do plano lingülstico ao plono discursivo. Rio de Janeiro: Foc. de Letras/UFR, 1991

政

DUCROT, G. Critique et clinique. Poris: Minuit, 1993 . In: GUIMARāes, E. (Org.). Histório e sentido na linguagem. Compinas, SP: Pontes, 1989.

EAGLETON, Terry. A ideologia da estética. Rio de Joneiro Zohor 1993

JAKOBSON, Romon. Lingǘstica e comunicacãõo. São Paulo: Cultrix, 1978

LACAN, Jacques. Television. Poris: Seuil, 1974.

_. Ecrits. Paris: Sevil, 1966

O seminório, XX. Rio de Joneiro: Zohar, 1982

Vers un signifitiont nouveou. In: Onnicar?, no. 17-18.

MAGNO, MD. Pedagogia freudiono. Ria de Janeiro: Imogo,

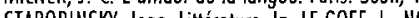

(1) Foris: Gollimord, 1974

28. MAGNO 1993. p. 65. 0 termo eventural foi foriado por Magno paro troduzir o termo événementiel, utilizado por Badiou para dizer daquilo que se apresenta como emergêncio do Verdade.

29. Cf. DE DUVE, 1989. p. 9-65.

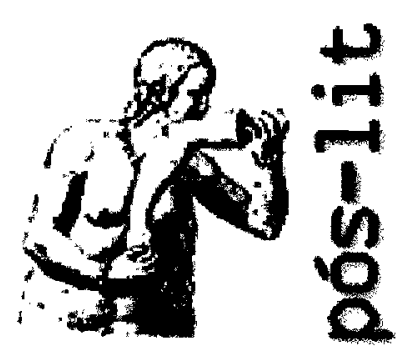

\section{Programa de Pós-Graduação em Letras: Estudos Literários da Faculdade de Letras da UFMG}

\author{
Artigo disponível em
}

http://www.letras.ufmg.br/poslit 